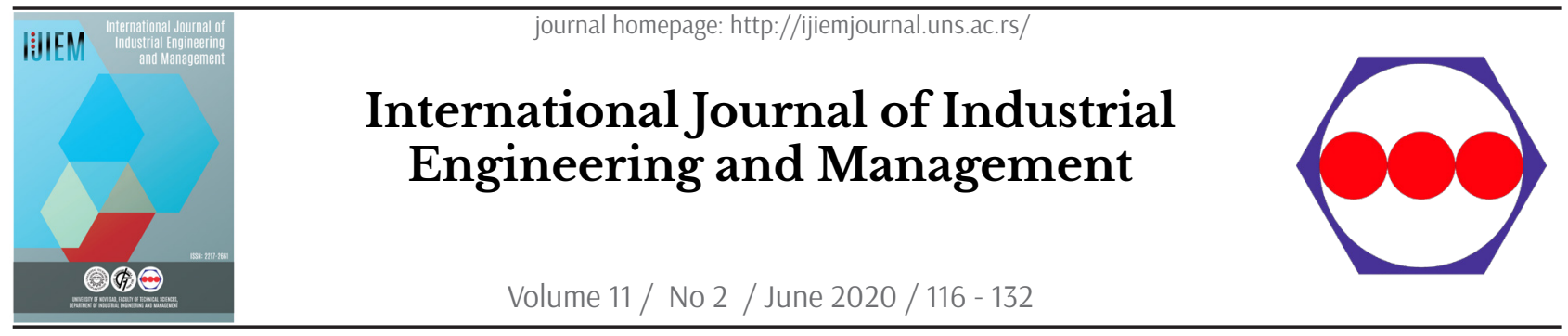

Original research article

\title{
Strategic management accounting and strategic management: The mediating effect of performance evaluation and rewarding
}

\author{
P. Petera *, J. Wagner, L. Šoljaková \\ University of Economics, Prague, Department of management accounting, Prague, Czech Republic
}

\begin{abstract}
A B STRACT
The purpose of this article is to investigate the mediating effect of performance evaluation and rewarding on the implementation of strategic management accounting (SMA) into strategic management. Although these issues have important consequences for managerial practice, they have yet to be empirically addressed by previous studies making this research more significant. A model was proposed and tested using partial least squares modeling. Data were collected via questionnaire from a random sample of 90 medium- and large-size businesses with two lines of mediation being considered. The first involves performance evaluation and performance-based rewarding of top management, while the second concerns the evaluation and rewarding of middle- and lower-level managers. A mediating effect does exist and is relatively strong. A practical implication of this study is the recommendation that companies should support the implementation of SMA into strategic management via performance evaluation of all managerial levels and performance-based rewarding of top managers. For middle- and lower-level managers, strategic performance-based rewards need to be carefully considered. Theoretically, this study pioneers the investigation of variables other than company performance as a dependent variable in SMA.
\end{abstract}

\section{ARTICLE INFO}

Article history:

Received December 18, 2019

Revised April 30, 2020

Accepted May 5, 2020

Published online May 19, 2020

Keywords:

Strategic management accounting;

Performance evaluation;

Rewarding;

Contingency theory

*Corresponding author:

Petr Petera

petr.petera@vse.cz

\section{Introduction}

Strategic management accounting (SMA) first appeared on the scene as a set of interconnected techniques and management approaches which could facilitate the incorporation of strategic thinking into management [1]-[3]. In terms of the highly competitive and turbulent environment, strategic thinking became a significant part of managerial work as high-quality strategy-focused management is of critical importance for success [4]-[7].

The use of SMA tools and techniques has been a favorite topic among academics and professionals over the last three decades. Reviewing the empirical research published in the literature, several blind spots in the puzzle of understanding the mechanism of SMA diffusion into strategic management became evident.

First, only a specific SMA technique or an incomplete set of techniques were usually investigated in previous research. Full attention was brought upon implementation details of such a tool, but the global perspective of an SMA agenda considering synergies and context was lost. Rather than focus on details, this research comprises "the big picture of the world of SMA".

Second, the use of some SMA tools is frequently considered as an independent variable explaining the performance of a company as a dependent variable, although the relationship between these two variables 
is too distant and, in this regard, weak. The decision to use performance of the company as a dependent variable is quite common in management accounting research (see e.g. [8] and [9]) as results are easy to interpret (if companies using a certain tool have significantly better performance than other ones, then we can state that there is positive effect of the use of this tool on performance). However, many such studies provide unconvincing results as performance is contingent upon numerous intervening variables. Moreover, the time lag between the adoption of a particular tool and its performance impact is difficult to consider.

Therefore, we suggest focusing on a more reasonable dependent variable. Specifically, the implementation of SMA into the strategic management control of the company is suspected to be the immediate result of using SMA tools. At first, we do not consider this as a self-evident matter. This approach reflects a stream of literature advocating that the formalistic adoption of some tools or technique is not useful per se and that the key step for success is the integration of a particular tool or technique into strategic management, i.e., turning a formalistic adoption into a living aspect of a managerial agenda.

Moreover, the relationship between the use (adoption) of an SMA tool and its implementation into strategic management needs more detailed research. We followed the ideas of [10] and [11], who state that one of the important factors influencing whether performance information is used in managerial activities is the degree to which stakeholders are involved in the whole system (e.g., buy-in of performance measurement by managers). Adhering to the findings of agency theory [12], we hypothesize that buy-in from managers, thanks to linking managers' performance evaluation, and rewarding with the use of SMA results in higher implementation of SMA into strategic management. Specifically, our research question is whether, and how strongly, performance evaluation and rewarding mediate the relationship between the use of SMA techniques and implementation of SMA into management control.

After identifying this research gap, we prepared a contingency-based empirical study aiming to investigate this mediating effect. Contingency theory [13][15] has a long tradition in management accounting research having been introduced into the field of management accounting in the 1970s and advocating the idea that appropriate properties of a management accounting system depend on circumstances, i.e., there is no universal best-fit solution for all situations. Numerous studies (e.g. [16]) demonstrate that con- tingency theory can be used to investigate both the mediating and moderating effect.

The research is based on 90 responses from a web-based survey conducted in 2018 among 1,000 medium- and large-size companies in the Czech Republic. We applied quantitative methodology, namely partial least squares structural equation modeling (PLS-SEM) [17], [18] which is used for data analysis. PLS-SEM has become an increasingly popular data analysis method, especially in recent years [19]. SmartPLS software, version 3.2.9, was used to process the data.

We believe this research has an important theoretical and practical contribution to be made. From the theoretical perspective, it contributes to understanding the mechanism of the techniques of SMA implementation into strategic management by investigating the moderating role of performance evaluation and rewarding. From a practical perspective, it helps owners (principals) to understand how to efficiently translate strategy into action using performance evaluation and rewarding systems for controlling managers (agents).

\section{Literature review and hypotheses development}

\subsection{Strategic management accounting and its implementation into strategic management}

The term Strategic Management Accounting (SMA) was pioneered in [20], [21] and defined as "the provision and analysis of management accounting data about a business and its competitors for use in developing and monitoring the business strategy".

The definition of SMA was consequently discussed in significant conceptual papers [22]-[26]. While some scholars tend to interpret SMA narrowly, a majority accepts a broader definition [20] and this approach is adopted in this article which is reflected in the operationalization of the construct "Strategic management accounting use" (SMAU), see the section on "Measurement of Constructs".

It was predicted [20] that SMA would spread quickly, both in practice and academia, but this prediction was not realized. On the other hand, interest in SMA gradually renewed and today there is a significant amount of research on this topic. There are over a hundred articles dedicated to SMA (if we apply a more narrow look and consider only articles published in high-quality journals indexed in Scopus or Web of Science), possibly even hundreds of articles 
(if we take into account all articles and conference papers), but it is beyond the scope of this research to address all of these articles.

There are three key types of articles on SMA theoretical (conceptual) ones, empirical case studies and empirical questionnaire surveys. Historically, questionnaire surveys on SMA were largely descriptive, but, consequently, they started to use a contingency approach, in addition to more and more sophisticated methodologies. Cadez and Guilding [27] were the first to employ structural modeling in the field of SMA and their paper addressed a package of SMA techniques and analyzed both contingent factors of SMA (i.e., factors which influence SMA adoption, in this case accountant participation in strategic processes, deliberate strategy formulation, market orientation, size of company and type of strategy ) and the consequences of SMA use (specifically its influence on performance). Since then, several papers aimed at the relationships between SMA and other constructs were published.
In Table 1 a summary of key constructs investigated in previous research on SMA can be found.

It is possible to conclude that the majority of studies investigated various contingency factors influencing the utilization of SMA techniques and not the consequences of SMA use. The studies analyzing consequences of SMA use or both contingent factors (i.e., determinants) and consequences of SMA use are in the minority and, as a result of SMA use, company performance is usually investigated.

The literature review, therefore, proved that despite there being ample SMA literature, it is still possible to identify significant research gaps in several meanings of this word.

First, from a geographical point of view, the area of Eastern and Central Europe is subject to less research aimed at SMA published in high-quality journals than Western Europe. There are numerous papers dealing with various individual tools of SMA (e.g., budgeting [43], activity based costing [44]-[45], Balanced Scorecard [46]), but not with SMA tech-

Table 1. Summary of key constructs investigated in previous studies on SMA

\begin{tabular}{|c|c|c|}
\hline Investigated factors influencing the use of SMA & Investigated consequences of SMA use & Article \\
\hline $\begin{array}{l}\text { governance and participation of accountants in } \\
\text { strategic management processes }\end{array}$ & None & {$[28]$} \\
\hline $\begin{array}{l}\text { competition and perceived environmental uncer- } \\
\text { tainty }\end{array}$ & None & {$[29]$} \\
\hline influence of company size and strategy type & None & {$[30]$} \\
\hline $\begin{array}{l}\text { perceived environmental uncertainty, historical per- } \\
\text { formance, life cycle stage, structure (centralization/ } \\
\text { decentralization), size of company, strategy type, } \\
\text { and quality of information system }\end{array}$ & None & [31] \\
\hline $\begin{array}{l}\text { historical performance, perceived environmental } \\
\text { uncertainty, proportion of service on total sales, } \\
\text { size, strategy type and top management team } \\
\text { characteristics }\end{array}$ & None & {$[32]$} \\
\hline $\begin{array}{l}\text { competition, dynamic use, dynamic tension, inter- } \\
\text { active use, membership in a group, proportion of } \\
\text { services on total sales, size, subsidiary }\end{array}$ & None & [33] \\
\hline perceived environmental uncertainty & None & {$[34]$} \\
\hline $\begin{array}{l}\text { company size, perceived environmental uncertainty, } \\
\text { strategy type, and industry }\end{array}$ & None & {$[35]$} \\
\hline $\begin{array}{l}\text { product characteristics, production technology, } \\
\text { information demand of managers, qualification of } \\
\text { accountants, business environment, size, and age }\end{array}$ & None & {$[36]$} \\
\hline company profile and manager profiles & None & {$[37]$} \\
\hline life cycle of a firm & company performance & [38] \\
\hline $\begin{array}{l}\text { accountant participation in strategic processes, } \\
\text { deliberate strategy formulation, market orientation, } \\
\text { size of company, strategy type }\end{array}$ & company performance & [27] \\
\hline differentiation strategy & exploratory innovation & [39] \\
\hline None & company performance & {$[40]$} \\
\hline None & $\begin{array}{l}\text { internal and external capabilities of a firm and } \\
\text { strategic position }\end{array}$ & [41] \\
\hline None & company performance & {$[42]$} \\
\hline Source: own literature review & & \\
\hline
\end{tabular}


niques as a whole.

It would be highly risky to suppose that imitating western approaches in other settings will bring the same results. For example, [47] found that cultural variables are critical for the selection of management tools. Research in Eastern and Central Europe is, therefore, highly needed.

Second, the previous part of this literature review revealed that, from the viewpoint of topics investigated, the majority of previous research in SMA focused on contingency factors of SMA. Studies investigating impacts of SMA on different factors are scarce and deal mostly with impacts on organizational performance.

Our study is distinctive from prior research in two key ways.

First, the approach taken in this article is innovative because it distinguishes the use of individual SMA techniques (SMAU) and the implementation of SMA into strategic management (Implementation). The underlying idea is that the use of individual SMA techniques is a prerequisite of the diffusion of SMA into a broader context of strategic management. This idea is in accordance with the stream of thinking advocating that it is necessary to differentiate between a formal adoption of performance measurement systems and their actual intensive use.

Second, it is supposed that the relation between SMA use and implementation of SMA into strategic management is not only direct, but also indirect through the utilization of performance evaluation and rewarding.

Last, but not least, it is possible to propose that previous studies focused on performance evaluation, rewarding and SMA in isolation, while this study more closely examines the interplay between individual constructs.

\subsection{Strategic Performance evaluation and rewarding}

Strategic performance evaluation and rewarding are strongly interconnected, yet separable approaches.

Thanks to performance evaluation, it is possible to understand the process of the subjective or objective evaluation of an employee's behavior. Generally, performance evaluation is considered a key component of management control systems which influences managerial behavior and performance [48]. Performance evaluation may be connected to rewarding (but not necessarily) and can be applied at all managerial levels [49], [50], [51].
Rewarding for performance is another tool of influencing employee motivation and behavior. On one hand, some researchers advocate that rewards for performance are counterproductive regarding work motivation [52]-[55]. On the other, the majority of scholars today advocate that correctly awarded rewards for performance are useful for motivating people in work settings [56]-[60].

Although the question regarding influence of performance evaluation and rewards on work motivation is important, we decided to focus our attention on the investigation of the mediating effect of performance evaluation and rewards on the degree of implementation of SMA into strategic management. As far as we know, this issue has not been addressed in any previous research.

\subsection{Research model and hypotheses}

The research model consists of SMA use as an independent variable, implementation of SMA into strategic management as a dependent variable, and performance evaluation and rewarding as mediating constructs. The detailed method of measurement of these constructs in the questionnaire is explained in the section "Materials and Methods", and the sub-section "Measurement of Constructs".

First, we propose that there is a direct positive relationship between the use of SMA techniques and implementation of SMA into strategic management. This relationship is in accordance with intuition and highlights the fact that a more or less formal use of SMA is a prerequisite to the integration of SMA into real business practice; more precisely - the degree of implementation positively depends on the degree of use of SMA techniques. It is possible to formulate H1: The degree of use of strategic management accounting techniques (construct SMAU) has a positive effect on implementation of strategic management accounting into strategic management (Implementation construct).

Second, we propose that there are also important indirect effects of SMA techniques used on SMA implementation through the utilization of performance evaluation and performance-based rewards. In the literature review, it was explained that performance evaluation of managers can be used with or without a link to rewarding for performance and it is rational to differentiate between performance evaluation of top managers and performance evaluation (connected with cascading strategy) of middle- and lower-level managers.

Psychology-based research [61], [62] suggests that 
extrinsic motivation (caused by external factors, such as performance evaluation and rewarding) can be internalized. Specifically, we therefore hypothesize that performance evaluation of top managers per se should have a positive influence on the "buy-in" of SMA by top managers and on their willingness to implement SMA into strategic management. The mentioned buy-in can be further strengthened by linking performance evaluation of top managers with their rewarding. Therefore, we hypothesize H2: Performance evaluation of top managers (PerfEvalTM construct) combined with rewarding of top managers (RewardsTM construct) has a positive effect on the implementation of strategic management accounting into strategic management (Implementation construct) and H3: Performance evaluation of top managers (PerfEvalTM construct) has a positive effect on the implementation of strategic management accounting into strategic management (Implementation construct).

Analogically, performance evaluation of middleand lower-level managers, together with a cascading strategy to these managers per se should have a positive influence on the "buy-in" of SMA by middle- and lower-level managers. The mentioned buy-in can be further strengthened by linking performance evaluation of middle- and lower-level managers with their rewarding. We therefore hypothesize $\mathrm{H} 4$ : A cascading strategy to middle- and lower-level management and performance evaluation according to strategic criteria (construct PerfEvalMLM) combined with rewarding of middle- and lower-level managers (construct RewardsMLM) has a positive effect on the implementation of strategic management accounting into strategic management (Implementation construct) and H5: Performance evaluation of middleand lower-level managers (PerfEvalMLM construct) has a positive effect on the implementation of strategic management accounting into strategic management (Implementation construct).

The hypothesized relationships between constructs are depicted in a model, which can be found in Figure 1.

\section{Materials and methods}

\subsection{Measurement of constructs}

The questionnaire investigated several key constructs. For the sake of this article, attention is focused on the following six constructs:

(1) individual SMA techniques use (SMAU),

(2) performance evaluation of top management (PerfEvalTM),

(3) rewarding of top management (RewardsTM),

(4) cascading strategy to middle- and lower-level management and performance evaluation according to strategic criteria (PerfEvalMLM),

(5) rewarding of middle- and lower-level management according to strategic criteria (RewardsMLM),

(6) implementation of SMA into strategic management (Implementation).

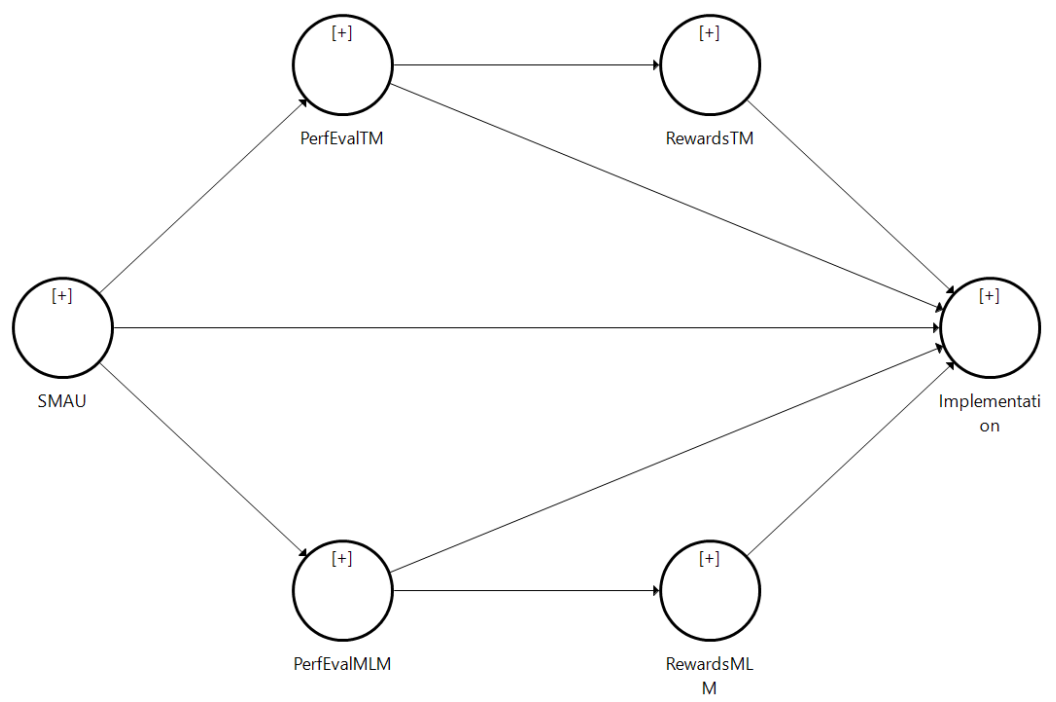

Figure 1. Structural model of relationships between use of individual SMA techniques and implementation of SMA into strategic management SMAU = degree of use of individual strategic management accounting techniques; PerfEvalTM = performance evaluation of top managers; RewardsTM = performance evaluation of top managers; PerfEvalMLM = cascading strategy to middle and lower management and performance evaluation according to strategic criteria; RewardsMLM = rewarding of middle and lower managers; Implementation = implementation of strategic management accounting into strategic management. 
These constructs were investigated via a measurement instrument, which is explained in Table 2 and Appendix 1. Regarding constructs used in management accounting, we were inspired by the comprehensive overview of this topic in [63].

The SMAU construct was intensively investigated in previous studies enabling it to be developed directly on the basis of previous literature ([27], [29], [30], [64]-[66]) and adapted to the specifics of Czech companies.

Other constructs are due to the innovative character of our unique model and have not been investigated before. These constructs were designed according to our knowledge of the field and, where possible, previously investigated and tested similar constructs were taken into account to prepare constructs of similar or higher quality. For example, rewarding of top management was not often investigated in management accounting literature and [67], who investigated the linking of PMS to reward mechanism, measured rewarding as a dummy variable (by the way, they also constructed this variable as an "ad hoc constructed instrument"). Compared to this approach, our instrument (see below) is a step forward.

The overview of constructs can be found in Table 2 and detailed wording of the questions in the questionnaire can be found in Appendix 1.

\subsection{Preparation of web-based questionnaire, sample and data collection}

The web-based questionnaire prepared in LimeSurvey was used as a tool for data collection. The final version of our questionnaire was developed over

Table 2. Constructs

\begin{tabular}{|c|c|c|c|}
\hline Construct & Variable abbreviation & Variable description & Measurement scale \\
\hline $\begin{array}{l}\text { Individual SMA techniques } \\
\text { use (SMAU) }\end{array}$ & $\begin{array}{l}\text { SMAU1 } \\
\text { SMAU2 } \\
\text { SMAU3 } \\
\text { SMAU4 } \\
\text { SMAU5 } \\
\text { SMAU6 } \\
\text { SMAU7 } \\
\text { SMAU8 } \\
\text { SMAU9 } \\
\text { SMAU10 } \\
\text { SMAU11 }\end{array}$ & $\begin{array}{l}\text { life-cycle costing } \\
\text { target costing } \\
\text { activity-based costing } \\
\text { quality costing } \\
\text { strategic costing } \\
\text { strategic pricing } \\
\text { strategic planning and budgeting } \\
\text { benchmarking } \\
\text { integrated PMS } \\
\text { customer accounting } \\
\text { competitor accounting }\end{array}$ & $\begin{array}{l}\text { scale } 1 \\
\text { scale } 1 \\
\text { scale } 1 \\
\text { scale } 1 \\
\text { scale } 1 \\
\text { scale } 1 \\
\text { scale } 1 \\
\text { scale } 1 \\
\text { scale } 1 \\
\text { scale } 1 \\
\text { scale } 1\end{array}$ \\
\hline $\begin{array}{l}\text { Performance evaluation of } \\
\text { top management (PerfE- } \\
\text { valTM) }\end{array}$ & $\begin{array}{l}\text { PerfEvalTM1 } \\
\text { PerfEvalTM2 } \\
\text { PerfEvalTM3 } \\
\text { PerfEvalTM4 } \\
\text { PerfEvalTM5 } \\
\text { PerfEvalTM6 }\end{array}$ & $\begin{array}{l}\text { customer perspective } \\
\text { employee perspective } \\
\text { internal processes } \\
\text { innovations } \\
\text { quality } \\
\text { social responsibility }\end{array}$ & $\begin{array}{l}\text { scale } 2 \\
\text { scale } 2 \\
\text { scale } 2 \\
\text { scale } 2 \\
\text { scale } 2 \\
\text { scale } 2\end{array}$ \\
\hline $\begin{array}{l}\text { Performance evaluation of } \\
\text { middle and lower manage- }\end{array}$ & $\begin{array}{l}\text { PerfEvalMLM1 } \\
\text { PerfEvalMLM2 } \\
\text { PerfEvalMLM3 }\end{array}$ & $\begin{array}{l}\text { meetings with middle and lower management } \\
\text { ongoing discussion across management levels } \\
\text { dialog and information sharing across all } \\
\text { managerial levels }\end{array}$ & $\begin{array}{l}\text { scale } 2 \\
\text { scale } 2 \\
\text { scale } 2\end{array}$ \\
\hline & PerfEvalMLM4 & $\begin{array}{l}\text { performance evaluation of middle and lower mgmt } \\
\text { according to strategic goals achievement }\end{array}$ & scale 3 \\
\hline $\begin{array}{l}\text { Rewarding of top manage- } \\
\text { ment (RewardsTM) }\end{array}$ & $\begin{array}{l}\text { RewardsTM1 } \\
\text { RewardsTM2 }\end{array}$ & $\begin{array}{l}\text { financial rewards of top management depend on the } \\
\text { performance of company } \\
\text { financial performance-based rewards are a significant } \\
\text { part of the total reward of top managers }\end{array}$ & $\begin{array}{l}\text { scale } 3 \\
\text { scale } 3\end{array}$ \\
\hline $\begin{array}{l}\text { Rewarding of middle and } \\
\text { lower management (Rewards- } \\
\text { MLM) }\end{array}$ & RewardsMLM1 & $\begin{array}{l}\text { Financial rewards of middle and lower management } \\
\text { for achievement of strategic goals are a significant } \\
\text { part of their total reward }\end{array}$ & scale 3 \\
\hline $\begin{array}{l}\text { Implementation of SMA } \\
\text { into strategic management } \\
\text { (Implementation) }\end{array}$ & $\begin{array}{l}\text { Implementation1 } \\
\text { Implementation2 } \\
\text { Implementation3 } \\
\text { Implementation4 } \\
\text { Implementation5 } \\
\text { Implementation6 } \\
\text { Implementation7 }\end{array}$ & $\begin{array}{l}\text { identification of strategic success factors } \\
\text { setting of strategic goals } \\
\text { evaluation of the achievement of strategic goals } \\
\text { information on variance from strategic goals } \\
\text { control of key strategic areas } \\
\text { utilization in meetings of top management } \\
\text { management of strategic uncertainties }\end{array}$ & $\begin{array}{l}\text { scale } 2 \\
\text { scale } 2 \\
\text { scale } 2 \\
\text { scale } 2 \\
\text { scale } 2 \\
\text { scale } 2 \\
\text { scale } 2\end{array}$ \\
\hline
\end{tabular}

*scale 1: 1=not used, 5=very intensively used; scale 2: 1=negligibly, 5=intensively, scale 3: 1=strongly disagree, 5=strongly agree Source: own computations 
several months and piloted by six specialists in the area of management accounting.

The population of this study are medium- and large-size companies (with more than 50 employees and with a turnover above 256 million CZK) from a wide range of industries domiciled in the Czech Republic. The overall amount of companies meeting our selection criteria was 3,938 according to the $\mathrm{Al}$ bertina CZ Gold Edition database. As it would be difficult to contact all these companies, 1,000 cross-industrial business companies were randomly selected. The contact information to these 1,000 companies was obtained in two phases. First, we obtained a phone contact from the Albertina database or from corporate web pages. Second, we contacted these companies by phone and asked them to participate in the research and, if they agreed, we asked them for an e-mail contact to a senior financial manager (e.g., $\mathrm{CFO}$ or financial director) or their personal assistant and explained to them the goals of our research. Finally, we sent an e-mail with a link to our web-based questionnaire to the contacted managers (one questionnaire per company, i.e., the unit of observation is a questionnaire per company). The survey was conducted from September 2018 to December 2018. In total, 90 useable questionnaires are analyzed in this article, i.e., a response rate of nine per cent. The response rate is typical (slightly above the average) for questionnaire surveys in the Czech Republic; unfortunately, not all companies indicating a possible interest in research consequently participated in this activity.

Descriptive characteristics of respondents can be

Table 3. Descriptive characteristics of respondents $(n=90)$ found in Table 3.

Nearly all respondents fulfilled the original screening criteria. Two responding companies had under 50 employees and three companies had turnover less than 250 million CZK, nevertheless the size of these companies was very close to the threshold criteria and were not excluded from the analysis.

Structurally, 50 companies belonged to the manufacturing industry, eighteen companies to the wholesale and retail industry, and seven companies to the construction industry. The other industries included three or fewer companies.

\section{Results}

This chapter presents the results of the analysis in two steps. First, the reliability and validity of measurement constructs are examined. Second, the evaluation of the hypotheses and model fit are provided. This is a standard procedure recommended by scholarly literature on the PLS-SEM approach ([17-19], [68]).

\subsection{Reliability and validity}

Reliability and validity of constructs and outer loadings for individual variables can be found in Table 4 . In the case of the RewardsMLM construct, it is impossible to evaluate its internal consistency because this construct is measured only by one item.

According to [17], Cronbach's Alpha, which measures the internal reliability of constructs, should ex-

\begin{tabular}{llll}
\hline Statistic & Full-time employees & $\begin{array}{l}\text { Assets } \\
\text { (thousands CZK) }\end{array}$ & $\begin{array}{l}\text { Turnover } \\
\text { (thousands CZK) }\end{array}$ \\
\hline Mean & 321.56 & $1,406,491$ & $1,712,720$ \\
Std. Error of Mean & 42.22 & 347,575 & 385,4466 \\
Median & 191 & 514,204 & 585,270 \\
Std. Deviation & 401 & $3,297,387$ & $3,656,664$ \\
Skewness & 3.931 & 6.227 & 6.229 \\
Kurtosis & 20.920 & 46.320 & 46.725 \\
Minimum & 46 & 62,070 & 173,146 \\
Maximum & 2,931 & $27,666,833$ & $30,900,714$ \\
25th percentile & 102.50 & 265,451 & 355,757 \\
75th percentile & 369.25 & $1,048,376$ & $1,431,773$ \\
\hline
\end{tabular}

Source: own calculations 
Table 4. Reliability and validity of constructs

\begin{tabular}{|c|c|c|c|c|c|}
\hline Constructs and variables & $\begin{array}{l}\text { Outer } \\
\text { loadings }\end{array}$ & $P$ values & $\begin{array}{l}\text { Cronbach's } \\
\text { Alpha }\end{array}$ & $C R$ & $\begin{array}{l}\text { Average variance } \\
\text { extracted (AVE) }\end{array}$ \\
\hline SMAU & & & 0.830 & 0.864 & 0.373 \\
\hline SMAU1 & 0.464 & 0.000 & & & \\
\hline SMAU2 & 0.735 & 0.000 & & & \\
\hline SMAU3 & 0.671 & 0.000 & & & \\
\hline SMAU4 & 0.711 & 0.000 & & & \\
\hline SMAU5 & 0.634 & 0.000 & & & \\
\hline SMAU6 & 0.668 & 0.000 & & & \\
\hline SMAU7 & 0.592 & 0.000 & & & \\
\hline SMAU8 & 0.644 & 0.000 & & & \\
\hline SMAU9 & 0.585 & 0.000 & & & \\
\hline SMAU10 & 0.471 & 0.000 & & & \\
\hline SMAU11 & 0.457 & 0.000 & & & \\
\hline PerfEvalTM & & & 0.820 & 0.869 & 0.526 \\
\hline PerfEvalTM1 & 0.691 & 0.000 & & & \\
\hline PerfEvalTM2 & 0.752 & 0.000 & & & \\
\hline PerfEvalTM3 & 0.688 & 0.000 & & & \\
\hline PerfEvalTM4 & 0.763 & 0.000 & & & \\
\hline PerfEvalTM5 & 0.664 & 0.000 & & & \\
\hline PerfEvalTM6 & 0.786 & 0.000 & & & \\
\hline PerfEvalMLM & & & 0.806 & 0.878 & 0.650 \\
\hline PerfEvalMLM1 & 0.889 & 0.000 & & & \\
\hline PerfEvalMLM2 & 0.874 & 0.000 & & & \\
\hline PerfEvalMLM3 & 0.867 & 0.000 & & & \\
\hline PerfEvalMLM4 & 0.543 & 0.000 & & & \\
\hline RewardsTM & & & 0.632 & 0.844 & 0.730 \\
\hline RewardsTM1 & 0.874 & 0.000 & & & \\
\hline RewardsTM2 & 0.835 & 0.000 & & & \\
\hline RewardsMLM & & & 1.000 & 1.000 & 1.000 \\
\hline RewardsMLM1 & 1.000 & & & & \\
\hline Implementation & & & 0.906 & 0.926 & 0.641 \\
\hline Implementation1 & 0.822 & 0.000 & & & \\
\hline Implementation2 & 0.821 & 0.000 & & & \\
\hline Implementation3 & 0.872 & 0.000 & & & \\
\hline Implementation4 & 0.768 & 0.000 & & & \\
\hline Implementation5 & 0.776 & 0.000 & & & \\
\hline Implementation6 & 0.820 & 0.000 & & & \\
\hline Implementation7 & 0.716 & 0.000 & & & \\
\hline Source: own calculations & & & & & \\
\hline
\end{tabular}


ceed 0.7. From Table 4 it is evident that for RewardsTM this criterion is not fulfilled because Cronbach's Alpha equals 0.632. Cronbach's Alpha is disposed to underestimate the internal consistency reliability and can, therefore, be considered too conservative a measure. Some scholars [69] consider the less conservative composite reliability (CR) to be a better measure of reliability than Cronbach's Alpha. For CR, acceptable values are between 0.70 and 0.90 with high values (above 0.95) undesirable. Results depicted in Table 4 show that CR is acceptable for all constructs.

Outer loadings are recommended to be over the common threshold of 0.7 [68]. Nevertheless, Hulland [70] noticed, in practical research, that at least some measures have loadings below 0.70 and recommended dropping items with loadings of less than 0.40 or 0.50 . In this study, all variables with outer loadings below 0.50 were excluded, i.e., the variables SMAU1, SMAU10, and SMAU11 were removed. All results in the following text are calculated after the exclusion of these variables.

On the construct level, convergent validity is usually evaluated via the average variance extracted (AVE) which should be higher than 0.50 [17]. Values under 0.50 may indicate issues with the internal consistency of constructs. This condition is not fulfilled for the SMAU construct even after the exclusion of variables with outer loadings below 0.50 AVE equal to 0.443 , which can be considered a borderline value.

Discriminant validity controls if the variables do not relate to more than one construct and there are several possible approaches to the evaluation of discriminant validity. The most commonly used is the Fornell-Larcker criterion [71] which compares the square root of the AVE with latent variable correlations. The Fornell-Larcker criterion is fulfilled when the square root of each construct's AVE is greater than its highest correlation with any other construct, see Table 5 .

Results in Table 5 show that the Fornell-Larcker criterion is fulfilled for all constructs because the square root of each construct (can be found in the intersection of row and column containing the given construct) is greater than the correlation of this construct with other constructs (correlations can be found under the square root of a construct).

A study [72] noticed that use of the Fornell-Larcker criterion for PLS-SEM models may be inaccurate and suggested using a heterotrait-monotrait ratio (HTMT) of the correlations. The threshold level of the HTMT is the subject of discussion, but the majority of scholars suggest a threshold of 0.85 . The HTMT criterion is shown in Table 6 .

It is possible to conclude that the HTMT criterion is also fulfilled and discriminant validity is therefore corroborated both by the Fornell-Larcker criterion and HTMT criterion.

The variance inflation factor (VIF) reflects the collinearity in data behind the constructs. The threshold value is five and the value of VIF greater than five

Table 5. Discriminant validity, Fornell-Larcker

\begin{tabular}{lllllll}
\hline Construct & Implementation & PerfEvalMLM & PerfEvalTM & RewardsMLM & RewardsTM & SMAU \\
\hline Implementation & 0.801 & & & & \\
PerfEvalMLM & 0.652 & 0.807 & & & \\
PerfEvalTM & 0.485 & 0.565 & 0.725 & & \\
RewardsMLM & 0.197 & 0.531 & 0.292 & 1.000 & 0.435 & 0.855 \\
RewardsTM & 0.445 & 0.515 & 0.415 & 0.192 & 0.242 & 0.665 \\
SMAU & 0.646 & 0.563 & 0.517 & & \\
\hline
\end{tabular}

Source: own calculations

Table 6. Discriminant validity, Heterotrait-monotrait ratio (HTMT)

\begin{tabular}{|c|c|c|c|c|c|c|}
\hline Construct & Implementation & PerfEvalMLM & PerfEvalTM & RewardsMLM & RewardsTM & SMAU \\
\hline \multicolumn{7}{|l|}{ Implementation } \\
\hline PerfEvalMLM & 0.746 & & & & & \\
\hline PerfEvalTM & 0.552 & 0.677 & & & & \\
\hline RewardsMLM & 0.204 & 0.622 & 0.325 & & & \\
\hline RewardsTM & 0.582 & 0.753 & 0.573 & 0.553 & & \\
\hline
\end{tabular}

Source: own computations 
may indicate a potential collinearity problem [17].

On the basis of the results depicted in Table 7, it is possible to summarize that VIF is not greater than five for any variable, i.e., there is no collinearity in our data.

\subsection{Results of structural model and evaluation of hypotheses}

Evaluation of the measurement model proved that its properties are acceptable, and it is possible to continue the analysis with an assessment of the structural model.

Results of the path analysis can be seen in Figure 2.

Figure 2 shows the path coefficient and statistical significance (p-values) of relationships between constructs. Results show that implementation of SMA into management is greatly explained by the model. The coefficient of determination (R2) represents the

Table 7. Collinearity statistics, VIF

\begin{tabular}{|c|c|}
\hline Variable & VIF \\
\hline SMAU2 & 1.752 \\
\hline SMAU3 & 1.640 \\
\hline SMAU4 & 1.759 \\
\hline SMAU5 & 1.501 \\
\hline SMAU6 & 1.585 \\
\hline SMAU7 & 1.330 \\
\hline SMAU8 & 1.974 \\
\hline SMAU9 & 1.900 \\
\hline PerfEvalTM1 & 1.411 \\
\hline PerfEvalTM2 & 1.761 \\
\hline PerfEvalTM3 & 1.875 \\
\hline PerfEvalTM4 & 2.070 \\
\hline PerfEvalTM5 & 1.925 \\
\hline PerfEvalTM6 & 2.389 \\
\hline PerfEvalMLM1 & 3.020 \\
\hline PerfEvalMLM2 & 2.679 \\
\hline PerfEvalMLM3 & 2.264 \\
\hline PerfEvalMLM4 & 1.149 \\
\hline RewardsTM1 & 1.271 \\
\hline RewardsTM2 & 1.271 \\
\hline RewardsMLM1 & 1.000 \\
\hline Implementation1 & 2.465 \\
\hline Implementation2 & 2.502 \\
\hline Implementation3 & 3.973 \\
\hline Implementation 4 & 2.331 \\
\hline Implementation5 & 2.223 \\
\hline Implementation6 & 2.529 \\
\hline Implementation7 & 1.715 \\
\hline
\end{tabular}

Source: own calculations 
combined impact of exogenous constructs on an endogenous construct, i.e., the amount of variance in the endogenous construct explained by exogenous constructs. Therefore, the higher the values of R2, the better the predictive abilities of a model.

Specifically, our model explained a $55.8 \%$ variance in the Implementation construct, a $31.7 \%$ variance in the PerfEvalMLM construct, a 28.2\% variance in the RewardsMLM construct, a 26.7\% variance in the PerfEvalTM construct and a $17.2 \%$ variance in the RewardsTM construct. In the context of social sciences, these results are fully acceptable, though the amount of explained variance in the key Implementation construct is especially high.

The analysis of inner models should not be limited to direct relationships. Our hypotheses relate to mediation effects and the model specifically includes more than one mediating variable, i.e., a multiple mediation analysis is required and specific indirect effects need to be calculated for an evaluation of the hypotheses. Results can be found in Table 8.

Hypotheses H1, H2 and H5 are supported by the results, but hypotheses $\mathrm{H} 3$ and $\mathrm{H} 4$ are rejected. Although there is a positive specific indirect effect of SMAU on Implementation through PerfEvalTM, it is not statistically significant. The specific indirect effect of SMAU on Implementation through PerfEvalMLM and RewardsMLM is statistically significant but negative.

\section{Discussion}

The results proved that the measurement model does not suffer from any substantial issues from a statistical point of view. The only problem is with AVE for the SMAU construct which has a borderline value. It was, therefore, possible to advance the analysis and assess the structural model.

Table 8. Evaluation of hypotheses

\begin{tabular}{|c|c|c|c|c|}
\hline Hypothesis & Description & Coefficient & P-value & Result \\
\hline $\mathrm{H} 1$ & SMAU $\rightarrow$ Implementation & 0.386 & 0.001 & supported \\
\hline $\mathrm{H} 2^{*}$ & $\mathrm{SMAU} \rightarrow$ PerfEvalTM $\rightarrow$ RewardsTM $\rightarrow$ Implementation & 0.046 & 0.039 & supported \\
\hline $\mathrm{H}^{*}$ * & $\mathrm{SMAU} \rightarrow$ PerfEvalTM $\rightarrow$ Implementation & 0.009 & 0.880 & rejected \\
\hline $\mathrm{H} 4^{*}$ & $\mathrm{SMAU} \rightarrow$ PerfEvalMLM $\rightarrow$ RewardsMLM $\rightarrow$ Implementation & -0.059 & 0.023 & rejected \\
\hline $\mathrm{H} 5^{*}$ & $\mathrm{SMAU} \rightarrow$ PerfEvalMLM $\rightarrow$ Implementation & 0.237 & 0.003 & supported \\
\hline
\end{tabular}

*Specific indirect effects are displayed here, not path coefficients Source: own computations

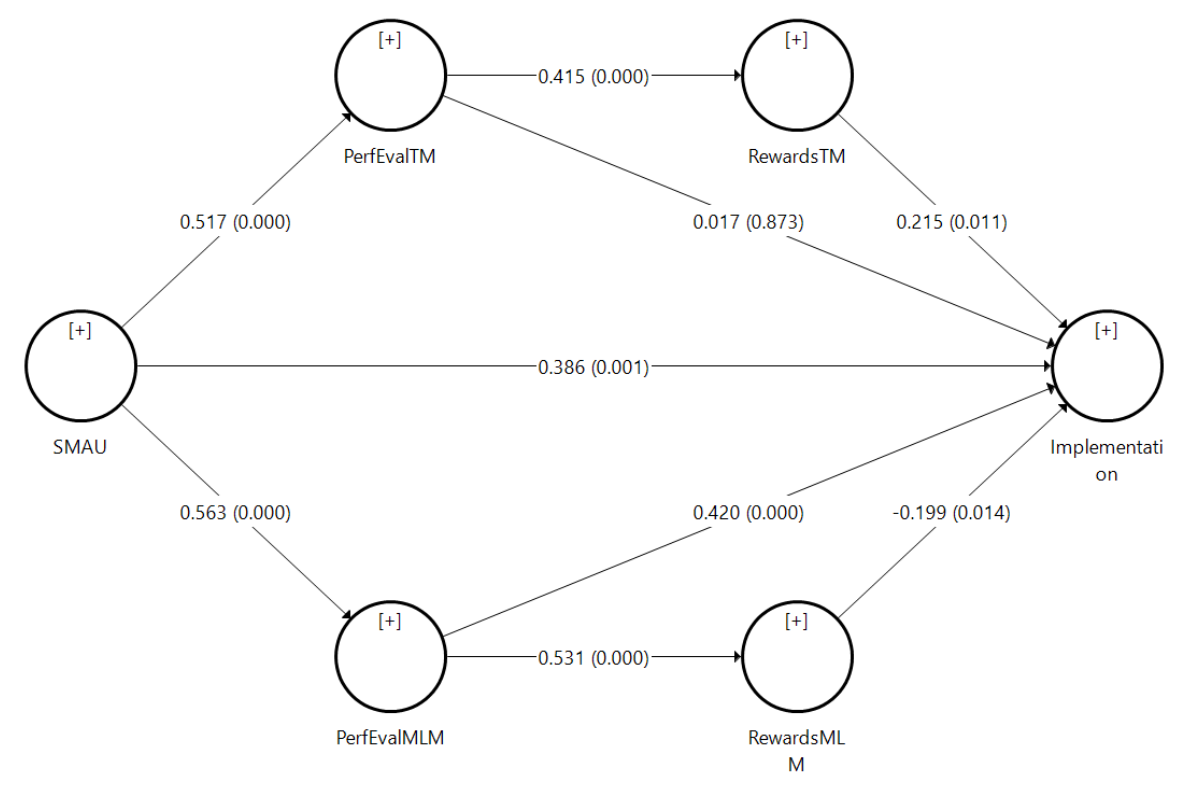

Figure 2. Results of path analysis 
The results show that regarding the key dependent construct Implementation, the model explained $55.8 \%$ of the variance in the construct. Acceptable levels of R2 differ across disciplines. Nitzl [73] reported that in the field of management accounting the average value of the main variables was approximately $33 \%$. It is, therefore, possible to advocate that, in the context of management accounting research, the amount of variance explained by our model represents an outstanding result.

We suggest that this result is partially caused by the fact that the dependent construct of our model (Implementation) has a close relationship with other constructs of the model and this relationship is not obfuscated by too many variables.

Evaluation of the hypotheses brought some significant findings and it is possible to summarize that the majority of results is in accordance with our expectations.

The direct effect of SMAU on Implementation is positive (path coefficient equals to 0.386 ) and statistically significant. This result is not surprising as it supports hypothesis $\mathrm{H} 1$ and implies that if companies use individual SMA techniques more intensively, they can also implement SMA into strategic management.

The total specific indirect effect of SMAU on Implementation is smaller than the direct effect, yet it is still positive and relatively strong (0.233). A more detailed analysis of this effect revealed expected results and one surprising result.

Utilization of the cascading strategy to middle and lower management, accompanied by their performance evaluation according to strategic criteria per se (without rewarding), has a positive and statistically significant effect on implementation of SMA into strategic management (hypothesis H5 is supported). Similarly, utilization of performance evaluation of top managers per se (without rewarding) has a positive effect on implementation of SMA into strategic management, but it is not statistically significant (hypothesis H3 is rejected). What is surprising is that while the specific indirect effect of SMAU on Implementation through PerfEvalMLM and RewardsMLM is positive and statistically significant (hypothesis H2 is supported), the specific indirect effect of SMAU on Implementation through PerfEvalMLM and RewardsMLM is negative (i.e., opposite to our expectations) and statistically significant (hypothesis $\mathrm{H} 4$ is rejected). This result is somewhat counterintuitive because it can be interpreted that performance evaluation of middle- and lower-level managers, the cascading strategy to these managers, in addition to rewarding of these managers on the basis of their strategic performance, decreases the implementation of SMA into strategic management.

It is possible to formulate several practical managerial implications of these results. First, our research confirmed that the degree of implementation of SMA into strategic management positively depends on the existence of the formal use (adoption) of strategic management accounting. Companies striving to integrate strategic issues in management should, therefore, adopt and use individual SMA tools as a first necessary step. This obvious result is in accordance with conventional wisdom, but statistical confirmation is needed. Second, the implementation of performance evaluation and rewarding of top managers according to strategic criteria have a positive influence on the degree of implementation of SMA into strategic management and companies should implement both these tools for top managers. Third, we discovered that the cascading strategy and performance evaluation of middle- and lower-level managers without rewarding (i.e., feedback per se) has a significant positive impact on the degree of implementation of SMA into strategic management. Finally, we are disappointed by the fact that the specific indirect effect of SMA use on implementation of SMA into strategic management through the combined use of performance evaluation of middle- and lower-level managers and performance-based rewarding of these managers was found to be negative and statistically significant. It is important to emphasize that it is necessary to be extremely cautious with any straightforward interpretation of this result.

We can only speculate on the reasons explaining this negative relationship between rewarding of middle- and lower-level managers and implementation of SMA. This may be caused by the fact that top managers believe that rewarding of middle- and lower-level managers, according to strategic criteria per se, integrates the strategy into management sufficiently and, therefore, it is not necessary to exert such a significant effort to integrate strategy by any other means. In order to discover the more complete truth concerning the reasons for this result, further research is needed.

Regarding the relevance of our research for academia, we propose that the main contribution of this article consists of three points: 1.) a radical abandonment of organizational performance as a key independent variable; 2.) a shift of focus to performance evaluation and rewarding for performance as important mediating variables; 3.) highlighting the idea that it is necessary to differentiate between the adoption and use of various SMA tools and the deep integra- 
tion of strategic thinking into management. On the basis of these statements, we suggest ideas for further research in the Conclusions which follow.

\section{Conclusions and limitations}

This study strove to investigate the mediating effect of performance evaluation and rewarding on the implementation of SMA into strategic management. Two lines of mediation were distinguished, the first through performance evaluation and performance-based rewarding of top management, the second through cascading performance measures to middle and lower management and subsequent performance evaluation and strategic performance-based rewarding of middle and lower management.

It was found that a mediating effect (in the terminology of PLS-SEM methodology a specific indirect effect) does exist and is relatively strong. Surprisingly, the specific indirect effect of SMA use on implementation of SMA into strategic management through the combined use of performance evaluation of middleand lower-level managers and performance-based rewarding of these managers was found to be negative and statistically significant. The direct effect of SMA use on implementation of SMA into strategic management is positive and statistically significant. Our results provided support for hypotheses $\mathrm{H} 1, \mathrm{H} 2$ and H5. Hypotheses H3 and H4 were rejected. We advocate that companies should support the implementation of SMA into strategic management through performance evaluation of all managerial levels, the cascading of such a strategy to middle and lower management, and performance-based rewarding of top managers. For lower managerial levels, strategic performance-based rewards need to be carefully considered and further research into this area is needed.

Limitations of this study include standard limitations stemming from the inherent features of the survey-based data. Another limitation is that our sample consisted of 90 units of analysis, an acceptable amount, similar to other questionnaire-based studies in the field of management accounting. Finally, the questionnaire deals with the subjective opinions of respondents, and it is possible that they do not represent the status quo in their organizations.

There are several possible avenues of further research. The first option is to replicate this research in other Eastern and Central European countries following minor improvements in the measurement instrument (e.g., measuring all constructs by at least two variables). A second possibility is the preparation of qualitative research in the form of a comparative multiple case study aimed at SMA adoption and use, and integration of strategic thinking into management. This research should address at least two cases: a company whose strategically based performance evaluation and rewarding is not implemented and a second company where SMA adoption and use is accompanied by performance evaluation and rewarding. It would be interesting to apply a theoretical stance such as a goal-setting theory or a self-determination theory to study how rewarding influences motivation at work and the behavior of various groups of employees.

\section{Funding}

This paper is an outcome of the "Effect of remuneration system and performance measurement system on employee motivation and behavior" project supported by Grant No. F1/25/2018, Internal Grant Agency of the University of Economics, Prague.

\section{References}

[1] Bhimani, A., \& Langfield-Smith, K. (2007), "Structure, formality and the importance of financial and nonfinancial information in strategy development and implementation," Management Accounting Research, Vol. 18, No. 1, pp. 3-31. doi:10.1016/j.mar.2006.06.005

[2] Bromwich, M. (1990), "The case for strategic management accounting: The role of accounting information for strategy in competitive markets," Accounting, Organizations and Society, Vol. 15, No. 1-2, pp. 27-46. doi: 10.1016/0361-3682(90)90011-I

[3] Gond, J-P., Grubnic, S., Herzig, C., \& Moon, J. (2012), "Configuring management control systems: Theorizing the integration of strategy and sustainability," Management Accounting Research, Vol. 23, No. 3, pp. 205-223. doi:10.1016/j.mar.2012.06.003

[4] Ax, C., \& Greve, J. (2017), “Adoption of management accounting innovations: Organizational culture compatibility and perceived outcomes," Management Accounting Research, Vol. 34,pp.59-74.doi:10.1016/j.mar.2016.07.007

[5] Chenhall, R. H. (2003), "Management control systems design within its organizational context: findings from contingency-based research and directions for the future," Accounting Organizations and Society, Vol. 28, No. 2-3, pp. 127-168. doi:10.1016/s0361-3682(01)00027-7

[6] Grinstein, A. (2008), "The effect of market orientation and its components on innovation consequences: A metaanalysis," Journal of the Academy of Marketing Science, Vol. 36, No. 2, pp. 166-173. doi: 10.1007/s11747-007-0053-1

[7] Kaplan, R., Cooper, R. (1998), "Cost and Effect: Using Integrated Systems to Drive Profitability and Performance," Boston: Harvard Business School Press.

[8] Dess, G. G., \& Robinson, R. B. (1984), "Measuring organizational performance in the absence of objective measures - the case of the privately-held firm and conglomerate business unit," Strategic Management Journal, Vol. 5, No. 3, 265-273. doi:10.1002/smj.4250050306

[9] Hamann, P. M., Schiemann, F., Bellora, L., \& Guenther, 
T. W. (2013), "Exploring the Dimensions of Organizational Performance: A Construct Validity Study," Organizational Research Methods, Vol. 16, No. 1, 67-87. doi:10.1177/1094428112470007

[10] Folz, D. H., Abdelrazek, R., \& Chung, Y. (2009), "The Adoption, Use, and Impacts of Performance Measures in Medium-size Cities: Progress Toward Performance Management," Public Performance \& Management Review, Vol. 33, No. 1, pp. 63-87. doi: 10.2753/pmr1530-9576330103

[11] Kroll, A. (2015), "Drivers of Performance Information Use: Systematic Literature Review and Directions for Future Research," Public Performance \& Management Review, Vol. 38, No. 3, pp. 459-486. doi:10.1080/15309576.2015.1 006469

[12] Jensen, M. C., \& Meckling, W. H. (1976), "Theory of firm: managerial behaviour, agency costs and ownership structure,” Journal of Financial Economics, Vol. 3, No. 4, pp. 305-360. doi:10.1016/0304-405x(76)90026-x

[13] Granlund, M., \& Lukka, K. (2017), "Investigating highly established research paradigms: Reviving contextuality in contingency theory based management accounting research," Critical Perspectives on Accounting, Vol. 45, pp. 63-80. doi:10.1016/j.cpa.2016.11.003

[14] Otley, D. T. (1980), "The contingency theory of management accounting: achievement and prognosis," Accounting, Organizations \& Society, Vol. 5, No. 4, pp. 413-428.

[15] Otley, D. (2016), "The contingency theory of management accounting and control: 1980-2014," Management Accounting Research, Vol. 31, pp. 45-62. doi: 10.1016/j.mar.2016.02.001

[16] Aguinis, H., Edwards, J. R., \& Bradley, K. J. (2017), "Improving Our Understanding of Moderation and Mediation in Strategic Management Research," Organizational Research Methods, Vol. 20, No. 4, 665-685. doi: $10.1177 / 1094428115627498$

[17] Hair, J. F., Hult, T. M., Ringle, C. M. and Sarstedt, M. (2017), "A Primer on Partial Least Squares Structural Equation Modeling (PLS-SEM)," Thousand Oaks, California: Sage Publications.

[18] Hair, J. F., Sarstedt, M., Ringle, C. M. and Gudergan, S. P. (2018), "Advanced Issues in Partial Least Squares Structural Equation Modeling,” Thousand Oaks, California: Sage Publications.

[19] Hair, J. F., Risher, J. J., Sarstedt, M., \& Ringle, C. M. (2019), "When to use and how to report the results of PLS-SEM," European Business Review, Vol. 31, No. 1, pp. 2-24. doi:10.1108/EBR-11-2018-0203

[20] Simmonds, K. (1981), "Strategic management accounting," Management Accounting, Vol. 59, No. 4, pp. 26-29.

[21] Simmonds, K. (1982), "Strategic Management Accounting for Pricing: A Case Example," Accounting and Business Research, Vol. 12, No. 47, pp. 206-214. doi: $10.1080 / 00014788.1982 .9728809$

[22] Langfield-Smith, K. (2008), "Strategic management accounting: How far have we come in 25 years?," Accounting, Auditing and Accountability Journal, Vol. 21, No. 2, pp. 204-228. doi:10.1108/09513570810854400

[23] Lord, B. R. (1996), "Strategic management accounting: The emperor's new clothes?," Management Accounting Research, Vol. 7, No. 3, pp. 347-366. doi: 10.1006/mare.1996.0020

[24] Ma, Y., \& Tayles, M. (2009), "On the emergence of strategic management accounting: An institutional perspective," Accounting and Business Research, Vol. 39, No. 5, pp. 473-495. doi:10.1080/00014788.2009.9663379

[25] Nixon, B., \& Burns, J. (2012), "The paradox of strategic management accounting," Management Accounting
Research, Vol. 23, No. 4, pp. 229-244. doi: 10.1016/j.mar.2012.09.004

[26] Roslender, R., \& Hart, S. J. (2003), "In search of strategic management accounting: Theoretical and field study perspectives," Management Accounting Research, Vol. 14, No. 3, pp. 255-279. doi:10.1016/S1044-5005(03)00048-9

[27] Cadez, S., \& Guilding, C. (2008), "An exploratory investigation of an integrated contingency model of strategic management accounting," Accounting Organizations and Society, Vol. 33, No. 7-8, pp. 836-863. doi: 10.1016/j.aos.2008.01.003

[28] Arunruangsirilert, T., \& Chonglerttham, S. (2017), "Effect of corporate governance characteristics on strategic management accounting in Thailand," Asian Review of Accounting, Vol. 25, No. 1, pp. 85-105. doi: 10.1108/ARA-11-2015-0107

[29] Cescon, F., Costantini, A., \& Grassetti, L. (2019), "Strategic choices and strategic management accounting in large manufacturing firms," Journal of Management and Governance, Vol. 23, No. 3, pp. 605-636. doi: 10.1007/s10997-018-9431-y

[30] Cinquini, L., \& Tenucci, A. (2010), :Strategic management accounting and business strategy: a loose coupling?," Journal of Accounting \& Organizational Change, Vol. 6, No. 2, pp. 228-259. doi:10.1108/18325911011048772

[31] Pavlatos, O. (2015), "An empirical investigation of strategic management accounting in hotels," International Journal of Contemporary Hospitality Management, Vol. 27, No. 5, pp. 756-767. doi:10.1108/ijchm-12-2013-0582

[32] Pavlatos, O., \& Kostakis, X. (2018), "The impact of top management team characteristics and historical financial performance on strategic management accounting," Journal of Accounting and Organizational Change, Vol. 14, No. 4, pp. 455-472. doi:10.1108/jaoc-11-2017-0112

[33] Siška, L. (2016), "The contingency factors affecting management accounting in Czech companies," Acta Universitatis Agriculturae et Silviculturae Mendelianae Brunensis, Vol. 64, No. 4, pp. 1383-1392. doi: 10.11118/actaun201664041383

[34] Costantini, A., \& Zanin, F. (2017), "The Effect of Perceived Environmental Uncertainty on the Use and Perceived Usefulness of Strategic Management Accounting: Some Empirical Evidence," Managing Global Transitions, Vol. 15, No. 4, pp. 379-398. doi:10.26493/1854-6935.15.379-398

[35] Petera, P., \& Šoljaková, L. (2020), "Use of strategic management accounting techniques by companies in the Czech Republic," Economic Research-Ekonomska Istrazivanja, Vol. 33, No. 1, pp. 46-67. doi: 10.1080/1331677X.2019.1697719

[36] Nguyen, D. T. P., Nguyen, L. T. H., Dao, D. P., \& Dang, G. H. (2019), "The determinants influencing managerial accounting in Vietnamese manufacturing and trading enterprises," Academy of Accounting and Financial Studies Journal, Vol. 23, No. 5.

[37] Almasan, A., Circa, C., Dobroszek, J., \& Zarzycka, E. (2019), "The assessed usefulness of management accounting in Romania and Poland: A comparative contingency-based study," Engineering Economics, Vol. 30, No. 3, pp. 253264. doi:10.5755/j01.ee.30.3.20483

[38] Pasch, T. (2019a), "Organizational lifecycle and strategic management accounting," Journal of Accounting and Organizational Change, Vol. 15, No. 4, pp. 580-604. doi:10.1108/JAOC-10-2018-(0108

[39] Pasch, T. (2019b), "Strategy and innovation: the mediating role of management accountants and management accounting systems' use," Journal of Management Control, Vol. 30, No. 2, pp. 213-246. doi: 10.1007/s00187-019-00283-y

[40] Alamri, A. M. (2019), "Association between strategic 
management accounting facets and organizational performance,” Baltic Journal of Management, Vol. 14, No. 2, pp. 212-234. doi:10.1108/BJM-12-2017-0411

[41] Yuliansyah, Y., Khan, A. A., \& Fadhilah, A. (2019), "Strategic performancemeasurementsystem, firmcapabilities and customer-focused strategy," Pacific Accounting Review, Vol. 31, No. 2, pp. 288-307. doi:10.1108/par-09-2018-0068

[42] Alabdullah, T. T. Y. (2019), "Management accounting and service companies' performance: research in emerging economies," Australasian Accounting, Business and Finance Journal, Vol. 13, No. 4, pp.100-118. doi: 10.14453/aabfj.v13i4.8

[43] Popesko, B., Novák, P., Dvorský, J., \& Papadaki, Š. (2017), "The Maturity of a Budgeting System and its Influence on Corporate Performance," Acta Polytechnica Hungarica, Vol. 14, No. 7, pp. 91-104. doi:10.12700/aph.14.7.2017.7.6

[44] Popesko, B., Papadaki, Š. Novák, P. (2015), "Cost and reimbursement analysis of selected hospital diagnoses via Activity-Based costing," E\&M Economie and Management, Vol. 18, No. 3, pp. 50-61. doi:10.15240/tul/001/2015-3-005

[45] Hudáková Stašová, L. (2019), "Evaluating the Use of the Activity Based Costing Method in the Construction Industry in the V4 Countries," International Journal of Industrial Engineering and Management, Vol. 10, No. 4, pp. 57-67. doi:10.24867/ijiem-2019-4-245

[46] Jeličić, D., \& Bojanić, R. (2015), "Implementation of the balanced Scorecard as an instrument of strategic contolling in the brewing industry," International Journal of Industrial Engineering and Management, Vol. 6, No. 4, pp. 191-198.

[47] de Waal, A. A., \& de Boer, F. A. (2017), "Project management control within a multicultural setting," Journal of Strategy and Management, Vol. 10, No. 2, 148-167. doi:10.1108/JSMA-03-2016-0020

[48] Bellavance, F., Landry, S., \& Schiehll, E. (2013), "Procedural justice in managerial performance evaluation: Effects of subjectivity, relationship quality, and voice opportunity,” British Accounting Review, Vol. 45, No. 3, pp. 149-166. doi:10.1016/j.bar.2013.06.013

[49] Greenberg, J. (1986), "Determinants of Perceived Fairness of Performance Evaluations," Journal of Applied Psychology, Vol. 71, No. 2, pp. 340-342. doi: 10.1037/0021-9010.71.2.340

[50] Kunz, J. (2015), "Objectivity and subjectivity in performance evaluation and autonomous motivation: An exploratory study," Management Accounting Research, Vol. 27, pp. 27-46. doi:10.1016/j.mar.2015.01.003

[51] Otley, D., \& Pollanen, R. M. (2000), "Budgetary criteria in performance evaluation: a critical appraisal using new evidence," Accounting Organizations and Society, Vol. 25, No. 4-5, pp. 483-496. doi:10.1016/s0361-3682(98)00031-2

[52] Deci, E. L. (1971), "Effects of externally mediated rewards on intrinsic motivation," Journal of Personality and Social Psychology, Vol. 18, pp. 105-115. doi:10.1037/h0030644

[53] Frey, B. S., \& Osterloh, M. (2005), "Yes, managers should be paid like bureaucrats," Journal of Management Inquiry, Vol. 14, No. 1, pp. 96-111. doi:10.1177/1056492604273757

[54] Kohn, A. (1993), "Why Incentive Plans Cannot Work," Harvard Business Review, Vol. 71, No. 5, pp. 54-63.

[55] Pfeffer, J. (1998), "Six Dangerous Myths about Pay," Harvard Business Review, Vol. 76, No. 3, pp. 109-119.

[56] Cerasoli, C. P., Nicklin, J. M., \& Ford, M. T. (2014), "Intrinsic Motivation and Extrinsic Incentives Jointly Predict Performance: A 40-Year Meta-Analysis,” Psychological Bulletin, Vol. 140, No. 4, pp. 980-1008. doi: 10.1037/a0035661

[57] Eisenberger, R., \& Cameron, J. (1996), "Detrimental Effects of Reward: Reality or Myth?," American Psychologist, Vol. 51, No. 11, pp. 1153-1166. doi:10.1037/0003066 X.51.11.1153
[58] Gerhart, B., \& Fang, M. (2015), "Pay, Intrinsic Motivation, Extrinsic Motivation, Performance, and Creativity in the Workplace: Revisiting Long-Held Beliefs,” Annual Review of Organizational Psychology and Organizational Behavior, Vol. 2, No. 2, pp. 489-521. doi: 10.1146/annurev-orgpsych-032414-111418

[59] Jenkins Jr., G. D., Gupta, N., Mitra, A., \& Shaw, J. D. (1998), "Are Financial Incentives Related to Performance? A Meta-Analytic Review of Empirical Research,” Journal of Applied Psychology, Vol. 83, No. 5, pp. 777-787.

[60] Shaw, J. D., \& Gupta, N. (2015), "Let the evidence speak again! Financial incentives are more effective than we thought," Human Resource Management Journal, Vol. 25, No. 3, pp. 281-293. doi:10.1111/1748-8583.12080

[61] Howard, J., Gagné, M., Morin, A. J. S., \& Van den Broeck, A. (2016), "Motivation profiles at work: A self-determination theory approach," Journal of Vocational Behavior, Vol. 95-96, pp. 74-89. doi:10.1016/j.jvb.2016.07.004

[62] Deci, E. L., Olafsen, A. H., \& Ryan, R. M. (2017), "Self-De termination Theory in Work Organizations: The State of a Science,” Annual Review of Organizational Psychology and Organizational Behavior, Vol. 4, No. 1, pp. 19-43. doi:10.1146/annurev-orgpsych-032516-113108

[63] Bedford, D. S., \& Speklé, R. F. (2018), "Constructs in survey-based management accounting and control research: An inventory from 1996 to 2015," Journal of Management Accounting Research, Vol. 30, No. 2, pp. 269-322. doi:10.2308/jmar-51994

[64] Cadez, S., \& Guilding, C. (2007), "Benchmarking the incidence of strategic management accounting in Slovenia," Journal of Accounting \& Organizational Change, Vol. 3, No. 2, pp. 126-146. doi:10.1108/18325910710756140

[65] Dmitrović-Šaponja, L., \& Suljović, E. (2017), "Strategic management accounting in the Republic of Serbia," Economic Research-Ekonomska Istrazivanja, Vol. 30, No. 1, pp. 1829-1839. doi:10.1080/1331677X.2017.1392884

[66] Guilding, C., Cravens, K. S., \& Tayles, M. (2000), “An international comparison of strategic management accounting practices," Management Accounting Research, Vol. 11, No. 1, pp. 113-135. doi:10.1006/mare.1999.0120

[67] Dossi, A., \& Patelli, L. (2008), "The decision-influencing use of performance measurement systems in relationships between headquarters and subsidiaries," Management Accounting Research, Vol. 19, No. 2, pp. 126-148. doi:10.1016/j.mar.2007.11.001

[68] Hair, J. F., Sarstedt, M., Pieper, T. M., \& Ringle, C. M. (2012), "The Use of Partial Least Squares Structural Equation Modeling in Strategic Management Research: A Review of Past Practices and Recommendations for Future Applications,” Long Range Planning, Vol. 45, No. 5-6, pp. 320-340. doi:10.1016/j.lrp.2012.09.008

[69] Werts, C. E., Linn, R. L., \& Jöreskog, K. G. (1974), "Intraclass Reliability Estimates: Testing Structural Assumptions," Educational and Psychological Measurement, Vol.34,No.1,pp.25-33.doi:10.1177/001316447403400104

[70] Hulland, J. (1999), "Use of partial least squares (PLS) in strategic management research: A review of four recent studies," Strategic Management Journal, Vol. 20, No. 2, pp. 195-204. doi:10.1002/(SICI) 1097-0266 (199902)20:2<195::AID-SMJ13>3.0.CO;2-7

[71] Fornell, C., \& Larcker, D. F. (1981), "Evaluating Structural Equation Models with Unobservable Variables and Measurement Error," Journal of Marketing Research (JMR), Vol. 18, No. 1, pp. 39-50. doi:10.2307/3151312

[72] Henseler, J., Ringle, C., \& Sarstedt, M. (2015), "A new criterion for assessing discriminant validity in variance-based structural equation modelin," Journal of the Academy of Marketing Science, Vol. 43, No. 1, pp. 115-135. doi:10.1007/s11747-014-0403-8 
[73] Nitzl, C. (2016), "The use of partial least squares structural equation modelling (PLS-SEM) in management accounting research: Directions for future theory development," Journal of Accounting Literature, Vol. 37, pp. 19-35. doi:10.1007/978-3-319-71691-6_7

\section{Appendix 1: Questions used for measurement of constructs}

Strategic management accounting use (construct SMAU): To which extent does your company utilizes the following techniques of strategic management accounting (answer on scale from $1=$ not used to $5=$ very intensively used)?

- Information on costs of products and/or services for a long-term or for a product (service) lifetime (life cycle costing).

- Setting of cost limits on the basis of market prices and requested profit margin of products and/or services (target costing).

- Determination of costs and valuation of activities (activity based costing).

- Identification and management of quality costs, i.e. costs associated with the creation, identification, repair and prevention of defects (quality costing).

- Separated measurement of strategic expenses (e.g. research and development), capital expenses and operational expenses (STRATEX/CAPEX/ OPEX).

- Analysis of strategic factors in the process of price setting (strategic pricing).

- Strategic planning and budgeting.

- Benchmarking (i.e. comparison of internal processes to an ideal standard).

- Integrated performance measurement and management systems (e.g. Balanced Scorecard).

- Information on value of customers (customer profitability analysis, customer life time value).

- Information on competitors (e.g. performance, market share, profitability, reduction of costs).

Performance evaluation of top managers (construct PerfEvalTM): To which extent are performance measures related to the following perspectives used for performance evaluation of top managers (answer on scale from $1=$ negligibly to $5=$ intensively)?

- Customer perspective (e.g. market share, satisfaction, customer retention).

- Employee perspective (e.g. satisfaction of em- ployees, fluctuation, training of employees).

- Operational perspective (e.g. productivity, safety, optimalization of time use).

- Innovations (e.g. results of research and development, success of new products/services).

- Quality (e.g. quality of products/services, defects, received awards).

- Social responsibility (e.g. environment, communities, public relations).

Performance evaluation of middle and lower management (construct PerfEvalMLM):

To which extent top managers employ tools of strategic management accounting for (answer on scale from $1=$ negligibly to $5=$ intensively).

- Utilization in meetings and discussions of middle and lower management.

- Utilization in meetings and ongoing discussion across managerial levels.

- Utilization in dialog and sharing of information between various managerial levels.

To which extent do you agree with the following statement: "Performance of middle and lower managers is primarily evaluated on the basis of their ability to fulfil strategic goals and goals deduced from strategic goals" (answer on scale from $1=$ strongly disagree to $5=$ strongly agree).

Rewarding of top management (construct RewardsTM): To which extent do you agree with the following statements (answer on scale from $1=$ strongly disagree to $5=$ strongly agree):

- Financial rewards of top managers increase accordingly to the extent to which are actual results better than planned results.

- Performance-based rewards are an important part of the total salary of top management.

Rewarding of middle and lower management (construct RewardsMLM): To which extent do you agree with the following statement (answer on scale from $1=$ strongly disagree to $5=$ strongly agree):

- Rewards of middle and lower management for fulfilling strategic goals and goals deduced from strategic goals represent a significant share of their total salary.

Implementation of SMA into strategic management (construct Implementation): To which extent top management implements tools of strategic management accounting in the following areas (answer on scale from $1=$ negligibly to $5=$ intensively): 
- Identification of strategic success factors (i.e. factors indicating fulfilment of a chosen strategy).

- Strategic goals setting.

- Evaluation of achievement of strategic goals.

- Information on variance of actual results from strategic goals.

- Control of key areas of strategic performance.

- Utilization in meetings and discussions within top management.

- Management of strategic uncertainties (e.g. factors, which may question the present strategy or provide opportunities for new strategic initiatives). 